\title{
Hodgkin's disease
}

\author{
R A WOOD
}

British Medical fournal, 1978, 1, 1329-1333

After the anaesthetic I found that they had biopsied my neck as well as my axilla. Waiting for the result was the bad bit-why do these things take four days to process, why hadn't they done

Hodgkin's disease is a progressive malignant disorder of lymphatic tissue. It provokes reaction in that tissue, spreads in it, and metastasises to non-lymphatic organs. It may cause fever, pruritus, and sweating, and in advanced cases acquired immune deficiency makes a patient susceptible to infection. Improved treatment in the last 30 years, based on understanding the disorder better, has made it one of the most treatable and curable cancers.

\section{Clinical history}

As a student I imagined I had Hodgkin's disease and was duly reassured. Since then I have ignored minor lymphadenopathy and found any excuse to avoid examination by a doctor. Some weeks ago, however, I noticed a fullness in my right axilla, and a sense of pressure when the arm was at my side. Last week, after confirming that I had considerable lymphadenopathy in the axilla, my family doctor arranged for surgical biopsy. The nodes were firm but not hard, regular, mobile, and quite painless. Glandular reaction to skin abrasion or infection would have been tender, so that seemed improbable. Glandular fever was unlikely for many reasons and, though I see tubercle in the course of my work, it would have been an odd place to develop that. There were no nodes elsewhere, and I could not palpate my liver or spleen. A routine chest $x$-ray examination had been negative six weeks before. There was no evidence of breast carcinoma, and I remember thinking that that would be an embarrassing way to go.

My peripheral blood, sent off under an assumed name, showed normal appearances, and my ESR was $2 \mathrm{~mm}$ in first hour. That ESR gave me the courage to talk to my doctor. He told me that he thought it might be Hodgkin's diseasewhich I had considered. My Mantoux was positive-not too strongly, but enough to make me feel that my $\mathrm{T}$ lymphocytes were still in business. Still, I would not have expected to have immunodeficiency, which is associated with advanced disease. My weight was unchanged and my appetite, as usual, was too good. I had no fever or night sweating, no pain in the affected glands on taking alcohol, and no itch. Again, this seemed reasonable as I would have expected my ESR to be raised if these features were present. But I remembered that I had had shingles last year in the S2 segment, an odd place to get it; at the time I had wondered if I might have a cord lesion at that level. Now I wonder if I might have an extradural deposit but surely, if $I$ had, it would have done something more in a year. Having had chickenpox twice as a child, I contented myself with the thought that I was sensitive to the herpes zoster virus.

Bridge of Earn Hospital, Bridge of Earn, Perth PH2 9AQ

R A WOOD, MB, FRCPED, consultant physician a frozen section and given me a quick verdict? By the time they finally told me that it was nodular sclerosing Hodgkin's disease I was glad to accept that that was all it was: by then I was firmly convinced that I had a poorly differentiated diffuse lymphoma. But I was worried to hear that it was present in both neck and axilla, and humiliated that I had not found the neck lesion myself.

\section{Conventional management}

The general principles of investigation and treatment of Hodgkin's disease are not controversial. For years we have known that after radiotherapy a good proportion of patients with local glandular disease survive in the long term. Since Peters showed that prognosis was improved if glands adjacent to those implicated were irradiated ${ }^{1}$ it has been important to establish the full extent of the disease. There is a better chance then of initial treatment eradicating it. In the last decade the prognosis of relapsed or advanced cases has been further revolutionised by combined chemotherapy. The Ann Arbor staging system is the basis for treatment: patients are classified I to IV by the extent of their disease (as assessed by routine tests, radiology, and marrow biopsy), and A or B according to the absence or presence of weight loss, fever, or night sweats. Thus in stage I there is localised lymph-node disease, and in stage IV there is diffuse disease of one or more extralymphatic tissues. Because abdominal glands are inaccessible, inevitably accurate staging includes invasive procedures.

If a patient is graded as stage IV, no further investigation is needed. Other patients now proceed to lymphography. This expert procedure outlines abdominal nodes but not those high in the abdomen, in the mesentery, or at the hilum of the spleen. Positive findings are made in about $25 \%$ of patients with disease clinically detected only above the diaphragm. If, after lymphogram, patients are stage IIIA or better, laparotomy is advised. The spleen is removed (though not in children) and the abdomen is searched thoroughly. Easily accessible or obviously diseased glands are biopsied, and a liver biopsy is taken. In younger women the ovaries are transposed to the mid-line, out of the line of fire for iliac nodal radiotherapy, should that be necessary. Some authorities, mindful of the good prognosis of good histology-stage IA of the diseasebelieve that laparotomy need not be carried out in young women if a lymphogram gives negative results.

\section{Histology}

Four types are recognised. ${ }^{2}$ These are lymphocyte predominant, nodular sclerosis, mixed cellularity, and lymphocyte depleted. The presence of sclerosis or predomination of lymphocytes over histiocytes and neoplastic cells indicates a 
better prognosis. Pooled data from several centres shows that poor histology, advanced stage, and B grading are interrelated in their association with a poor prognosis (table I).

TABLE I-Relationship of advanced stage, poor histology, and B staging with fatal outcome

\begin{tabular}{|c|c|c|c|c|}
\hline Clinical stage & $\begin{array}{l}\text { Good histology } \\
\text { LP or NS }\end{array}$ & $\begin{array}{l}\text { Bad histology } \\
\text { MC or LD }\end{array}$ & Grading & Deaths \\
\hline I \& II & 232 & 60 & A 246 & $12\left(5^{\prime \prime}{ }^{\circ}\right)$ \\
\hline III & 154 & 53 & $\begin{array}{ll}\mathrm{A} & 120 \\
\mathrm{~B} & 126\end{array}$ & $16\left(14^{\circ}{ }^{\circ}\right)$ \\
\hline IV & 70 & 37 & $\begin{array}{c}\text { B } 86 \\
\text { Mostly B }\end{array}$ & $46\left(43^{\circ}{ }_{0}^{\circ}\right)$ \\
\hline Deaths & $57\left(12^{\circ}\right)$ & $40(28 \%)$ & & \\
\hline
\end{tabular}

$\mathrm{LP}=$ Lymphocyte predominant. $\mathrm{NS}=$ Nodular sclerosing. $\mathrm{MC}=$ Mixed cellularity. $\mathrm{LP}=$ Lymphocyte predomina
$\mathrm{LD}=$ Lymphocyte depleted.

\section{Treatment}

Stages I and II, and IIIA are treated with supervoltage radiotherapy. Stages IIIB and IV are managed with combined chemotherapy. In stages I and II over $90^{\circ}{ }_{0}$ now survive five years, and most of these patients will be cured.

Since its introduction a decade ago quadruple chemotherapy has revolutionised treatment of advanced or recurrent Hodgkin's disease. In the UK the usual regimen is a variant of that described by Nicholson et $a l,^{3}$ and comprises mustine, vinblastine, procarbazine, and prednisolone (MVPP). This safe and well-tolerated regimen (table II) is usually repeated six times, with rest periods of a month, and offers remission rates of $70-80^{\circ}{ }_{0}$, depending on stage and previous treatment. It now seems likely that some of the $75^{\circ} \%$ survivors of chemotherapy at five years will remain free of disease in future. Poor results are obtained in some patients who have previously had chemotherapy, which possibly indicates tumour resistance to drugs given singly, or sequentially. Nevertheless, prednisolone may on its own relieve systemic symptoms, notably fever and night sweating. Combination chemotherapy should be given only by doctors experienced in its use, and able to deal effectively with the sort of overwhelming superinfection that can arise in a granulocytopenic, immunodeficient patient.

TABLE II-MVPP regimen (Adapted from Nicholson $e t a l^{3}$ )

\begin{tabular}{l|c|c|c}
\hline \multicolumn{1}{c|}{ Drug } & Dosage & Route & Day of course \\
\hline $\begin{array}{l}\text { Mustine } \\
\text { hydrochloride }\end{array}$ & $\begin{array}{r}6 \mathrm{mg} / \mathrm{m}^{2} \\
6 \mathrm{mg} / \mathrm{m}^{2}\end{array}$ & $\begin{array}{c}\text { Intravenously } \\
\text { Intravenously } \\
\text { Orinblastine } \\
\begin{array}{l}\text { Procarbazine } \\
\text { Prednisolone }\end{array}\end{array}$ & $\begin{array}{r}1 \text { and } 8 \\
\text { Orally } 8\end{array}$ \\
$\begin{array}{l}100 \mathrm{mg} / \mathrm{m}^{2} \\
40 \mathrm{mg} / \mathrm{m}^{2}\end{array}$ & $\begin{array}{c}\text { Orally inclusive } \\
1-14 \text { inclusive }\end{array}$ \\
\hline
\end{tabular}

Alternative regimens including bleomycin, adriamycin, and dacarbazine ${ }^{45}$ are probably as effective, but I doubt if they help patients who are, or have become, unresponsive to MVPP. The considerable improvement in 5-year survival for all patients with Hodgkin's disease since 1969 is probably almost entirely due to improved chemotherapy. ${ }^{6}$ Chemotherapy has been used to back up radiotherapy in earlier stages of the disease but myelotoxicity is a serious problem, and second malignancies seem to occur more often than predicted.

\section{How I would be investigated}

Even if the result of my repeat chest $x$-ray examination is negative I shall wish to have tomography. Early mediastinal disease would be no surprise given that I have disease in the axilla, lower cervical nodes, and quite probably the infraclavicular nodes that connect them. Liver and bone scans are sensible routines and I should prefer to omit liver function tests (which would probably confuse the issue), and skeletal survey (which seems irrelevant if a bone scan is to be done). In my case, I shall worry about the lumbosacral spineremembering my shingles last year. I will request that my marrow biopsy be postponed until after my lymphogram and, if my doctor insists on it, have it done while I am under an anaesthetic for my staging laparotomy.

I will have a lymphogram for two reasons. Disease might be observed at an early stage in nodes that could escape notice at laparotomy. The contrast will still outline the abdominal nodes for up to two years, and review films might show the site of recurrence if I fell ill within that time. With A staging I will go on to laparotomy, even if my lymphogram is positive. I shall choose a surgeon who regularly carries out the procedure. The benefit of splenectomy outweighs the disadvantage. It is the only way to diagnose disease in that commonly affected organ and, should it be diseased, radiotherapy is easier with it out of the way. I shall ask for low-dose heparin as a prophylaxis against venous thrombosis, and I will be up the day after operation. Knowing the slight infection risk after splenectomy I shall probably be unnecessarily nervous if there is the slightest hint of fever.

\section{How I would be treated}

While my wound is healing and my health is improving I shall concern myself closely with plans for my radiotherapygiven that I am IIIA or better. I will want to get good treatment of the infraclavicular nodes, and I know that that will mean that there will be apical fibrosis and a lifelong risk of tuberculosis and mycetoma. I hope that I shall have no obvious mediastinal disease or early lung infiltration and I shall not need wide-field irradiation that would cause me to get lung fibrosis medially. If I had mediastinal disease I would ask for split-course radiotherapy in the hope that as the nodes regressed-which would be slow in nodular sclerosis-the area could be narrowed. I would not like chemotherapy to shrink my glands, as this would delay a procedure in which I had more faith.

Whether or not the disease has spread to my mediastinum, I shall want to have para-aortic treatment-after a four-week rest. If my abdomen is affected I shall have standard treatment, including to the splenic axis if my spleen is diseased. I shall be prepared to have radiotherapy of localised diseased bone or pulmonary infiltration. If the latter was more than minimal I would opt for drug treatment. My radiotherapy will be as an inpatient, and, as a person who enjoys peace and quiet, I should like a single room. I would spend my weekends at home so that my children would not have to travel in and out of hospital to see me. When I am stronger I will take a holiday in the sun. I will not be too neurotic over the next three years because I know that all is not lost even if the disease recurs. Most of the problems after radiotherapy should be gone within a few weeks but I realise that there is a prospect of my being slightly dyspnoeic on exertion on a long-term basis, and I am a little worried about the possible long-term result for the head of my right humerus, which cannot be protected during major axillary radiotherapy.

Should disease recur in a previously untreated glandular site I will have further radiotherapy. Otherwise it will be chemotherapy, as it would be with stage IIIB or IV disease at the outset.

The thing I would dislike about quadruple chemotherapy would be the drips, twice each course for the mustine. I would want both chlorpromazine and metoclopramide an hour beforehand, and I would prefer my treatments in the evening so that I could sleep off the worst of the nausea. I am not yet sufficiently convinced that a less toxic mustard would do as well, so I shall take mustine. But I will not take full dosage in my first course. I would hope that the mustine and vinblastine might be cut from $6 \mathrm{mg} / \mathrm{m}^{2}$ to $4 \mathrm{mg} / \mathrm{m}^{2}$, or less still if I had had extensive 
radiotherapy. If need be, white count and platelets permitting, my dose can be built up to the maximum by the third course. Too often I have seen patients develop profound marrow depression and overwhelming superinfection with bacteria or fungi. Although they have survived, their morale has been harmed and they are that much more debilitated. No, I will hope to reach my maximum dose by degrees and, if need be, I will submit to an extra course or two.

While I am having my nine months' course of chemotherapy I shall expect to carry on my work, something which most of my own patients manage to do. I will want to be given further MVPP if I deteriorate after a good response to earlier six-course chemotherapy. Some of my patients do well enough with the occasional single course in these circumstances, and do not seem to need a full rerun for another nine months. If I reach the position of failing to respond to MVPP I will submit to alternative drug regimens-but with little confidence or hope.

Unless it is through over-vigorous treatment, dying of
Hodgkin's disease is not sudden. Generally, death is from infection and exhaustion, and that never seems too distressingat least from the observer's point of view. Knowing what is happening may make it worse, and it would be irritating to die from a disease when that outcome is becoming rarer. Survival is far more likely, and the experience of serious illness would probably be good for my future practice, though I would be happier to forego the experience and continue to treat patients with cancer without being a victim myself.

\section{References}

${ }^{1}$ Peters, M V, Cancer Research, 1966, 26, 1232.

2 Lukes, R J, et al, Cancer Research, 1966, 26, 1311.

${ }^{3}$ Nicholson, W M, et al, British Medical fournal, 1970, 3, 7.

${ }^{4}$ Bonnadonna, G, et al, Cancer, 1975, 36, 252.

${ }^{5}$ Lokich, J J, et al, Cancer, 1976, 38, 667.

${ }^{6}$ Aisenberg, A C, and Qazi, R, Cancer, 1976, 37, 2423.

\title{
Today's Treatment
}

\section{Diseases of the respiratory system}

\section{Neoplasms of the lung}

\author{
E D GILBY
}

Neoplasms of the lung cause 33000 deaths a year in England and Wales and remain the commonest of all cancers. There are four common histological subtypes: epidermoid (squamous) carcinoma, anaplastic small cell (oat cell) carcinoma, adenocarcinoma, and large cell anaplastic carcinoma. The first two appear to be induced by smoking, but the last two may not be entirely related to the habit. While stopping smoking has no influence on the established case, giving up may halt or reduce the increasing risk of cancer from continued smoking. Attempts to cure the established condition fail in all but a fortunate $5-7 \%$.

\section{Clinical presentation, diagnosis, and staging}

The presenting symptoms usually occur against a background of chronic bronchitis of variable degree. Invasion of the bronchial mucosa by the primary lesion results in cough, increased sputum production, and haemoptysis. Distal bronchial occlusion is responsible for shortness of breath and bacterial pneumonia. Owing to the central position of most lesions one lobe or a whole lung is frequently affected. Extension into

\footnotetext{
Department of Radiotherapy and Oncology, Royal United Hospital, Bath BA1 3NG

E D GILBY, MSC, MRCP, consultant physician in medicine and oncology
}

regional lymph nodes and adjacent tissues may cause features such as paralysis of the phrenic nerve, Horner's syndrome, hoarseness, superior vena caval obstruction, dysphagia. Less commonly, metastases in distant sites produce the first symptoms, and no tissues appear to be immune to the ultimate spread.

A straight posteroanterior (PA) chest radiograph usually displays the primary lesion, but it can often be located better by a penetrated PA and a lateral film. Doubtful cases should be submitted to mediastinal tomography to delineate the lesion. Measurement of its dimensions is desirable to assess the respcnse to treatment, but the margins are often indistinguishable $\mathrm{f}$. $\mathrm{sm}$ the mediastinal structures or distal lung consolidation.

Sputum cytology may confirm malignancy. Success depends largely on the care with which the samples are collected Early morning "deep sputum" samples should be collected fir- five consecutive days. Histological confirmation should always be sought when the diagnosis is doubtful or when results of treatment are to be reported. The introduction of the flexible fibreoptic bronchoscope has made visualising lesions beyond the reach of the rigid bronchoscope much easier, but the latter is still preferred in certain cases. Biopsy should be attempted whenever technically possible.

Metastatic spread has occurred by the time the patient presents in more than $80 \%$ of small cell carcinomas and in $50-60 \%$ of the other cell types. This fact has been inferred, firstly, from screening patients with bone scintiscans and radiographs of bone and scintiscans and ultrasound scans of the liver, and, secondly, from the appearance of metastases after apparently complete surgical resection of the primary lesion.

A staging system using the TNM system may be used to describe the spread of disease in the newly diagnosed case. ${ }^{1}$ 